\title{
Research on Teaching Carrier and Elements
}

\author{
Jun-an Zhang ${ }^{1, a}$ and Tianxia Zhang ${ }^{2, b}$ \\ ${ }^{1}$ Shanghai University of Medicine \& Health Sciences, 200120, China \\ 2 Shanghai REIYI Culture Communications Co. Ltd., 201600, China

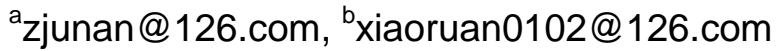

Keywords: Teaching elements; teaching carrier; teaching implementation; practice teaching; teaching on real-time tracking; teaching method.

\begin{abstract}
Teaching carrier is the carrier of information storage and carrying teaching, has its unique function and connotation, and is objective existence elements of teaching. The careful designs, accurately grasp the teaching carrier, are the precondition for the smooth completion of the teaching work, and are a key to the success or failure of the education teaching goal. Through the analysis of the teaching elements in the carrier of teaching and teaching media, teaching methods, teaching content and so on, the paper put forward the real-time tracking the implementation of the teaching method and practice teaching. Teaching practice has proved that this scheme has the distinct characteristics of The Times, comply with the basic law of teaching, and achieve the expected teaching goal.
\end{abstract}

\section{Introduction}

First of all, we have to figure out what is the "elements"? Simply elements is "to form the necessary factors of things", and "factor" is "constitutes the essence of, decide the success or failure of the things reasons or conditions"[1]. So the meaning of the element can be expressed as: to form the necessary ingredients, essence or decide the success or failure of the things necessary reasons or conditions, both must be included in the things make things. The modern system theory argues that both its substantive things, and may be regarded as a system, each part of the whole system is a things. Is the unity of opposites and system and element, under certain conditions, the system and the elements can be changed? Elements such as the solar system relative to the universe are, for the earth's system. Therefore, elements should be relatively independent.

Carrier can usually refer to the storage, carrying other objects [2]. Originally there is a clear statement of the in chemical reaction, it is to point to make some kind of chemical reaction is more sufficient, let the material by some special material to carry into the reaction, but this kind of special material itself does not participate in chemical reactions, no change before and after, this kind of material is called a carrier. The role of the carrier is mainly two aspects, one is storage and carry other things; the second is to promote the reaction between other things. Teaching is the activity of interaction between teachers and students. Teaching activities is the teachers have a purpose, conscious, in a planned way affect students, change the status of body and mind, prompting the development of practice. Interaction between teaching and learning to hair, teaches to have response, otherwise it doesn't work, can't call it a success.

\section{Carrier of Teaching is the Key Element of Teaching}

The teaching process of information transmission is different from general information transmission process, not only considering the transmission; more should consider "information response" after the information is received. This requires teaching process also needs information carrier that is usually called as teaching carrier, to prompt reaction and interaction between teaching and learning. So, what is the carrier of teaching? Teaching carrier is the carrier of information storage, carrying teaching, is a teacher for a certain teaching target, in under the guidance of the corresponding teaching strategies in order to pass the teaching content and design of a combined form of teaching content and form. 
Teaching material is the sorting, enrichment of teaching content, in order to make students better understand the master to achieve the teaching goal, teaching content, therefore, teaching materials and courses are the carrier. Teaching need the carrier, in addition to teaching is the activity of interaction between teachers and students, but also in the teaching process is a special kind of cognitive process. In the process of teaching, the students master knowledge many over the direct experience of the stage, the study of knowledge requirements contracted, through actively guide of the teacher, learned a lot of indirect knowledge system[3]. Consequently the content of teaching cannot be directly projected on the sensory systems to master knowledge, and through reasonable combination of the content, using the carrier to make students master the knowledge; highly efficient which is one of the existence conditions of teaching carrier. On the other hand, teaching is a purpose of propagation behavior. In order to effect change students, must depend on design to use a good carrier to achieve this effect. Carrier of teaching and teaching media, teaching methods, teaching content and so on has a very close correlation factors of teaching [4]. But the carrier is an independent teaching factors, it is associated with these elements have distinction.

\subsection{Carrier of Teaching and Teaching media}

Teaching media is a recognized teaching element, it comes from information dissemination. Generally believe that the media is carrying, passing information between sources and recipients of any material. Different teaching media and teaching carrier is mainly in the following two aspects. First of all, the media is a kind of communication channels, communication tools, is hardware. Carrier is the combination of content and form is software. The content of the second pass is different.

We can see between the source and receiver except material tools, there are the elements of information coding[5]. Therefore, if we define the media to convey information of material tools and not to extend the meaning of words, so the teaching media and carrier should be tied in two separate elements of information transfer process. Media in teaching content combination configuration and transmission tools were independent of each other, that is to say, even if the carrier and conveyance of combination known as the teaching media, also can't cancel the teaching carrier independent connotation and characteristics of it, cannot ignore teaching carrier as independent factors exist in the process of teaching.

\subsection{Carrier of Teaching and Teaching Methods.}

No matter how to define the teaching method at present, the teaching method is defined as teaching methods, measures, methods, strategies, but one thing in common is to identify a variety of definition, teaching method does not include the teaching content. It's just a generalization of optimization of teaching behavior. Therefore, it cannot be equated with teaching carrier, carrier cannot replace teaching.

\subsection{Carrier of Teaching and Teaching Content.}

Teaching carrier is storage, carrying the carrier of teaching information content, it is generally not teaching content. It is not the cognitive object. It merely promotes cognitive effect. Textbooks from the perspective of the carrier, for example, it is a kind of teaching content into the carrier of symbols, words, forms. Through learning materials for students master rich teaching contents of the textbooks. Textbook so that students do not need to remember all the words on the content. We hear a lot; read a good book should be read as "thin". That is to say, the teaching material of teaching content, absorb the essence part, the part of the carrier role natural discarded books will be read as "thin". Teaching is teaching content rich, full, storage system, continuous special symbols, words, teaching in the form of carrier. Is commonly used in the teaching of teaching carrier only storage, carrying a certain part of teaching content, the form is more flexible, created by teachers at any time, compilation. The same teaching content is a good teacher can design all kinds of rich teaching carrier, to pass the teaching content, the teaching fascinating, can learn more. Without experience and ability of teachers can only refer to the ready-made carrier - textbooks, scripted, an inflexible teaching form, students' cognitive response is often severe enough. 


\section{Teaching method in Real-time Tracking}

Real-time tracking method, through an open teaching plan, dynamically adjust the outline of the knowledge, use the Internet network dynamic real-time tracking subject development, weekly issue of e-books, encouraging students to participate in the project and writing essays, build We Chat, QQ group, keep learning exchange information, support for students to make full use of social networking platform show ego, sharing information, realized the teaching material and the latest dynamic real-time synchronization, self-independence of globalization, personalized teaching and learning resources, teaching is learning, has a certain reference value[6].

\subsection{Teaching Materials is too Difficult}

Current textbooks are written by teachers, the teachers at the time of writing textbooks focus on the integrity of knowledge representation, systemic and novelty, seldom consider easy absorption of knowledge from the perspective of students. In the case of knowledge to accelerate the update, now materials are widespread trial time too short is directly put into use, the several factors increased the difficulty of teaching high school students to master the teaching material content, how to reduce the difficulty of the teaching material? We use the method in the teaching process of the teaching material of Word electronic documents released on e-learning platform, designated part of the plan, teaching students to participate in the open after download to start the Word revision of the function of teaching material, modified to tag, don't know where to adjust discourse is not the right place, finally conducted by teachers' quality, comprehensive changes to the text, finalized version of the open teaching plan, makes the difficulty of the teaching material and the learning curve for each level after a learning is lower[7].

\subsection{Teaching Materials is too Old}

With the accelerating development of technology, the spread of knowledge and aging are also accelerating, school teaching content aging is serious, a lot of discipline in many university professors in the social practice is no longer use outdated knowledge. This will require us to change the traditional teaching content organization methods. Teachers should be put forward on the basis of teaching material related to textbook knowledge, these knowledge into keyword combination, according to the teaching material of each web page in the Internet supply, the greater the supply of the web pages that use the more people, therefore the greater the supply of web pages related knowledge as students must master the knowledge. Web supply smaller knowledge that academic circles familiarity with lower or less popular knowledge, the academic community can be used as a course paper topics or have a choice.

\subsection{The Latest Development of Real-time Tracking Course}

Teachers weekly tracking Baidu Library or periodical of library provides the latest literature, selected using offline page software after the latest week and save content of courses, during the preparation before class, this week will be filtered and previous literature combination, to find a suitable for interpretation of the literature in the classroom, in the literature and the key points in the teaching content. By teachers in the classroom, at the same time, according to the textbooks order based on the teaching material combined with the electronic album weekly deeply discusses teaching relevant knowledge. Practice proved that the Internet can fully guarantee the latest literature knowledge of novelty and interesting.

\subsection{How to Evaluation}

Examination is divided into three parts: one is the review course work or materials, second, the innovative idea; three is a paperless course completion examination.

Review class paper can copy everywhere, the main training student's text search ability and comprehensive ability. Innovative ideas discussed conception or theory by requirement has the originality and novelty, not the same as in the Internet or journals. Students at the time of conception design problems should be paid attention to the practicality and novelty, and does not require the number of words, as long as the realistic creative ideas. Exam is mainly in the electronic teaching platform "paperless examination". Give priority to with operation problem. After students receive topic, according to the topic request, will result documents submitted back to the server, so that teachers can be more comprehensive understanding of the students' practical ability. In order to better 
play its role, make the real-time tracking teaching teachers can implement open examination question bank, namely oneself by title appraisal by the students themselves. Let the students between grades each other and put forward amendments.

\subsection{How to Accumulate Teaching Process Data}

Open teaching platform such as High-quality Courses is used to establish an open and sharing community, according to the need to partition, including the teacher recommended papers read area, teachers of information announcement, student posts area, students free discussion, students area to the teacher's question, and irrigation area and so on. Platform has strong tracking function, for each resource teacher released; platform for each of the students' reading situation has carried on the follow-up. So we can be very convenient to know every student's study time length, the study situation, learning interest, homework completion point.

\section{The Organization and Implementation of Practice Teaching}

Practice has proved that practical teaching in training students' skills at the same time, has the important role of cultivating students' comprehensive quality, is an important means of cultivating students' innovative consciousness and creative ability and measures[6,7].

\subsection{Build Different Forms of Practice Teaching}

Build different forms of practice teaching. Such as empty recess experiment practice, concentrated practice; Campus experiment practice, off-campus practice, course design, graduation practice, comprehensive training program, training experiment practice, design and innovative practice, etc.

\subsection{Restructuring Practice Teaching Content and Time of Innovation}

The original curriculum design and practice teaching more focused on the end of the course focus on a few weeks. Generally result is actual laboratory utilization rate of each semester at the beginning, more free time, and at the end of the semester due to the relatively concentrated training, training rooms overload, sometimes conflict. Will now practical link in teaching with the usual, ensure training laboratory utilization balanced on one hand, on the other hand made students theory and practice, the training effect.

\subsection{Build Student Achievement Appraisal Way and the Index System}

Evaluation of student performance and should not be limited to the theory question paper grades, should reform the evaluation index system of the courses. On the one hand the basic theory of knowledge system can through the question paper exam form evaluation, on the other hand, fully considering the nature of the course, practice teaching link of the course, students should be combined with practice performance assess, or in the last performance appraisal, evaluation in the form of the written test, the combination of multiple evaluation methods can give full play to the students' various ability, improve students' comprehensive quality.

\subsection{Establish the Practice Teaching Process Management and Quality Assurance}

Practical teaching link can be reflected in the teaching plan, is only part of the work done. Whether to implement practical teaching link, guarantee the quality of practice, is the key to carry out the higher vocational education teaching goal. We strengthen the management of practical teaching process, to ensure strict according to teaching plan execution, and has strict requirements to the practice teaching teachers, ensure to achieve the goal of practice teaching.

\subsection{Standard Practice Results Archive System}

On the basis of the original work, written document must require practice results classified archive, currently stored in my department reference room, easy to find later.

\section{The Teaching Practice and Effect}

Fundamentals of Electric Circuits is the basis of the electrical or related professional core courses, Over the years, after careful study, explore and absorb the achievements of the reform of education teaching, the course from traditional teaching in theory, the theoretical analysis as the main teaching mode gradually transition to give priority to with practical teaching and theoretical knowledge as the auxiliary teaching mode, and design, complete a set of system, a complete system of teaching quality 
evaluation, evaluation[8,9]. By 327 students participate in teaching experiment reform tracking, investigation and evaluation of statistical analysis results showed that (table 1) : students' practical ability, theoretical level and comprehensive ability were improved significantly, has reached the expected course teaching effect.

Table 1327 students participate in the teaching reform of the teaching effect of statistics

\begin{tabular}{ccccc}
\hline Numble & Teaching evaluation & Good & Qualified & Unqualified \\
\hline 1 & Professional ability & $85.5 \%$ & $12.5 . \%$ & $2.0 \%$ \\
2 & Methods ability & $75.3 \%$ & $21.5 \%$ & $3.2 \%$ \\
3 & Social ability & $79.3 \%$ & $17.2 \%$ & $3.5 \%$ \\
\hline
\end{tabular}

\section{Conclusion}

We are teaching carrier as a factor to analyze the teaching research, mainly due to the carrier itself is very important for the influence of the teaching process of teaching, the nature and characteristics of itself, there are many worthy of in-depth study. In addition, the study of teaching carrier is conducive to our understanding of the nature of teaching process and operation.

The value on teaching carrier analysis and research includes three aspects, That is, to deepen the understanding of teaching the nature and characteristics, conducive the teachers' skills and the ability of teaching research and conducive to the teachers' creativity. Understanding of teaching carrier is conducive to better grasp the teaching target, teaching content, curriculum standard, the relationship between the teaching materials, teaching method.

\section{Acknowledgment}

This work was financially supported by Shanghai Medical Instrumentation College Scientific Research Innovation Fund (2015).

\section{References}

[1]. Li Bingde, Teaching Theory, People's Education Press, Peking, 2011: pp. 288-289.

[2]. Zhang Chuting, “Teaching Elements Hierarchy Theory”, Education Research, 2000.6: pp. 65-69.

[3]. Zhou Bing-feng, Xie Xin-shui and Liu Xing-qi, “Teaching Elements and Effect Evaluation of Micro-courses in University”, Modern Education Technology, Vol.25, No.9, PP. 30-36, 2015.

[4]. Jiang Dayuan, "Philosophical Reflections on a Systematic Curriculum Exploitation of Working Process,” Vocational Education Research in Xinjiang, 2010, 01(1):pp.1-6.

[5]. Huang Di, Xie Jia-jun and Hu Qi, "Exploration of the way to Develop the Project Teaching Carrier of Electrical Courses in Higher Vocational College”, Higher Education Forum, 2012.01(1). pp. 123-125

[6]. Shen Yang and Zhang Yechao, "Real-time Tracking Teaching Method", The national institutions of higher learning education annual meeting and academic seminar of technology cooperation committee(CA),2007.

[7]. The system administrator, "Teaching carrier is an independent element of teaching," http://www.njzhzx.net(DB/OL), 2014-02-16/2015-09-20.

[8]. Zhang Jun-an, Zhang Xin and Wang Li, “Competency-based Teaching Discussion and Practice on the Course Fundamentals of Electric Circuits,” Lecture Notes in Electrical Engineering 227 LNEE, n VOL. 5, pp. 527-532, 2013.

[9]. Zhang Jun-An, Qiao Ling-Ai, Zhang Xin and Tong Qing, "Design and Analysis of Practice Teaching Carrier on the Course Fundamentals of Electric Circuits," Vocational Education Research. pp 103-106, 2014(07). 